\title{
A MATERIALIZAÇÃO DO DESENVOLVIMENTO SUSTENTÁVEL, O DIREITO AO LAZER E A IDEIA DE DEMOCRACIA
}

THE MATERIALIZATION SUSTAINABLE DEVELOPMENT, THE RIGHT TO LEISURE AND DEMOCRACY IDEA

\author{
Bruna Adeli Borges ${ }^{1}$
}

SUMÁRIO: Introdução; 1 . Desenvolvimento sustentável; 2 . O direito social ao lazer; 3. A ideia de democracia; considerações finais; referências das fontes citadas.

\section{RESUMO}

O presente artigo parte do conteúdo da materialização do desenvolvimento sustentável, tendo em vista que mantém o progresso humano não apenas em alguns lugares, mas em todo do mundo, na medida em que o homem evolui surgem novas necessidades vitais, abordando a expansão das liberdades como ideal para o desenvolvimento humano, como proposto por Amartya Sem. Destacam-se os direitos sociais, com especial ênfase ao direito social ao lazer como um direito fundamental que tem eficácia e aplicabilidade constitucionalizada e, por fim, a noção de democracia que consiste em um dos pontos considerados mais importantes das sociedades modernas e contemporâneas. Assim, parte da seguinte problemática jurídica: quais as necessárias contribuições teóricas e pragmáticas para a implementação, manutenção e evolução do desenvolvimento sustentável no mundo contemporâneo e como imaginar a efetivação direito social ao lazer diante deste contexto? Apresenta a relevância do desenvolvimento dirigido por uma sustentabilidade organizada e concretizada nas políticas públicas. Refletindo a importância da participação ativa da sociedade como elemento fundamental para o progresso humano, buscando a eficácia do direito social ao lazer. Conclui-se que, um cidadão dotado de possibilidades para contribuir com a concretização de um regime democrático fortalece e incentiva os homens a viver e atuar no espaço público, agindo continuamente para incitar uma evolução sadia e que respeite os ditames da Democracia.

\footnotetext{
${ }^{1}$ Mestre em Direto pela Faculdade Meridional - IMED. Pós- Graduada em Direito Civil e Processual Civil pela Universidade de Passo Fundo- UPF. Graduada em Direito pela Universidade de Passo Fundo - UPF. Lattes: http://lattes.cnpq.br/8210489605739125. E-mail: brunadeli@ibest.com.br
} 
BORGES, Bruna Adeli. A materialização do desenvolvimento sustentável, o direito ao lazer e a ideia de democracia. Revista Eletrônica Direito e Política, Programa de Pós-Graduação Stricto Sensu em Ciência Jurídica da UNIVALI, Itajaí, v.11, n.3, 30 quadrimestre de 2016. Disponível em: www.univali.br/direitoepolitica - ISSN 1980-7791.

Palavras-chave: Desenvolvimento Sustentável, Sustentabilidade, Direito social ao lazer, Democracia.

\section{ABSTRACT:}

This article is part of the contents of the materialization of sustainable development, with a view to maintaining human progress not only in some places, but throughout the world, as man evolves there are new vital needs, addressing the expansion of freedoms as ideal for human development, as proposed by Amartya Sen. There is social rights, with special emphasis on the social right to leisure as a fundamental right that is effective and constitutionalized applicability and finally, the notion of democracy that consists of one of the points considered most important modern and contemporary societies. So part of the following legal issues: what are the necessary theoretical and pragmatic contributions to the implementation, maintenance and evolution of sustainable development in the contemporary world and to imagine the social right effectuation leisure before this context? It shows the relevance of the development led by an organized and implemented sustainability in public policy. Reflecting the importance of the active participation of society as key to human progress, seeking the effectiveness of the social right to leisure. In conclusion, a citizen endowed with opportunities to contribute to the achievement of a democratic system strengthens and encourages men to live and work in the public space, continuously acting to encourage a healthy evolution and respects the dictates of democracy.

Key-Words: Sustainable Development, Sustainability, Social Right to leisure, Democracy.

\section{INTRODUÇÃO}

O processo de intensificação da sociedade mundial produz uma série de modificações interligadas ao modelo do Estado moderno, a expansão das comunicações, do comércio, a preocupação ambiental e outros assuntos avançaram, gerando um espaço globalizado no meio de tantas transformações. No entanto, a participação ativa da sociedade é fundamental para que haja um Desenvolvimento Sustentável, tendo em vista que este mantém o progresso humano não apenas em alguns lugares, mas em todo do mundo, pois na medida em que o homem evolui surgem novas necessidades vitais. 
BORGES, Bruna Adeli. A materialização do desenvolvimento sustentável, o direito ao lazer e a ideia de democracia. Revista Eletrônica Direito e Política, Programa de Pós-Graduação Stricto Sensu em Ciência Jurídica da UNIVALI, Itajaí, v.11, n.3, 30 quadrimestre de 2016. Disponível em: www.univali.br/direitoepolitica - ISSN 1980-7791.

A relevância do desenvolvimento dirigido por uma sustentabilidade conduz à organização da economia, fortalece as Políticas Públicas, os recursos ambientais, bem como os recursos disponíveis. A contribuição de Amartya Sen para o estudo do artigo faz compreender o fenômeno do desenvolvimento, que através do conceito de liberdade pode-se ilustrar numa perspectiva o direito social ao lazer, que é um direito fundamental e cita-se como o estilo de vida das pessoas, a sua atitude de satisfação do indivíduo e o tempo disponível da pessoa com a sociedade, estes são os componentes constitutivos do desenvolvimento.

Deste modo, a partir desta nova visão acerca dos direitos sociais, obrigatoriamente existe a necessidade de abrangência e entendimento das transformações pela ciência jurídica, inclusive, tendo por esteira o direito positivo. Especialmente, em torno da aplicação do direito social ao lazer, o qual, aos poucos, tem gerado dúvidas e incertezas que surgiram de dissídios filosóficos e desaguaram na pragmática.

Com extrema relevância para desempenhar o processo das liberdades no direito social ao lazer, há que se demonstrar o desenvolvimento da expansão das liberdades criando oportunidades sociais, onde as políticas públicas e a sociedade têm papéis amplos no fortalecimento da proteção das capacidades humanas. A ideia de democracia faz com que se busque a implementação de políticas públicas efetivas para implementação do lazer a todos os seres humanos. A essência da Democracia funda-se na ideia de que a decisão deve abranger a escolha da maioria, de maneira a cumprir a função de ser modelo de governo eficiente para o povo.

O problema desta pesquisa pode ser descrito na seguinte indagação: quais as necessárias contribuições teóricas e pragmáticas para a implementação, manutenção e evolução do desenvolvimento sustentável no mundo contemporâneo e como imaginar a efetivação do direito social ao lazer diante deste contexto?

A hipótese de solução para essa pergunta surge a partir da visão diferenciada do papel do desenvolvimento sustentável, o avanço tecnológico e a modernização social; da efetivação e implementação do direito social ao lazer e da noção de 
BORGES, Bruna Adeli. A materialização do desenvolvimento sustentável, o direito ao lazer e a ideia de democracia. Revista Eletrônica Direito e Política, Programa de Pós-Graduação Stricto Sensu em Ciência Jurídica da UNIVALI, Itajaí, v.11, n.3, 30 quadrimestre de 2016. Disponível em: www.univali.br/direitoepolitica - ISSN 1980-7791.

democracia. A partir deste cenário, a teoria do desenvolvimento surge como fundamento para estabelecer os vínculos de uma sociedade equilibrada, democrática e com desenvolvimento sustentável.

O objetivo geral deste estudo é investigar a possibilidade de efetivação do desenvolvimento sustentável e a implementação do direito ao lazer através de políticas públicas. Os objetivos específicos podem ser descritos como: 1) verificar a eficácia e a aplicabilidade das normas constitucionais que contêm direitos sociais, especialmente, ao lazer; 2) avaliar a forma de desenvolvimento como expansão da liberdade no direito social ao lazer e sua eficácia no desenvolvimento sustentável; 3) analisar a democracia diante do contexto social.

O estudo utiliza como critério metodológico para o relato dos resultados apresentados, o método dedutivo, assim como as técnicas de pesquisa

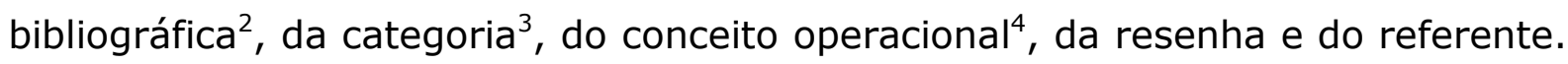
Além destes, outros podem ser acionados para que o aspecto formal deste estudo se torne esclarecedor ao leitor.

Os fundamentos teóricos desse artigo são caracterizados por autores como Amartya Sen, Neuro José Zambam, John Rawls, Márcio Ricardo Staffen, Sérgio Ricardo de Aquino, Nelson Carvalho Marcellino, Beatris Francisca Chemin, Robert Dahl, Noberto Bobbio, Paulo Bonavides, entre outras leituras necessárias e trazidas para elucidar o presente estudo.

\footnotetext{
2 "(...) Técnica de investigação em livros, repertórios jurisprudenciais e coletâneas legais". PASOLD, Cesar Luiz. Metodologia da pesquisa jurídica: teoria e prática. 12. ed. Florianópolis: Conceito Editoria/Millenium, 2011, p. 207.

3 "(...) palavra ou expressão estratégica à elaboração e/ou expressão de uma ideia" PASOLD, Cesar Luiz. Metodologia da pesquisa jurídica: teoria e prática, p.25.

4 "(...) uma definição para uma palavra ou expressão, com o desejo de que tal definição seja aceita para os efeitos das ideias que expomos" (...) PASOLD, Cesar Luiz. Metodologia da pesquisa jurídica: teoria e prática, p.37
} 
BORGES, Bruna Adeli. A materialização do desenvolvimento sustentável, o direito ao lazer e a ideia de democracia. Revista Eletrônica Direito e Política, Programa de Pós-Graduação Stricto Sensu em Ciência Jurídica da UNIVALI, Itajaí, v.11, n.3, 30 quadrimestre de 2016. Disponível em: www.univali.br/direitoepolitica - ISSN 1980-7791.

\section{DESENVOLVIMENTO SUSTENTÁVEL}

A sociedade moderna apresenta cenários inquietantes a cada dia informações se renovam sobre a crise ambiental. Urgem preocupações que desafiam os humanos, pois, as degradações feitas contra a natureza são incessantes, a exemplo, nas mudanças climáticas, o que antes parecia distante já chegou, o cotidiano mudou, contudo, há uma tolerância ${ }^{5}$ dos seres humanos para com o exercício dos limites, guiado pela ausência de consciência para com a justiça ecológica.

As complexidades do mundo globalizado tornam impossível soluções rápidas, os desafios que se colocam na problemática ambiental se enquadra no âmbito da governança, pois contempla a participação de vários atores transpassando fronteiras e a soberania dos Estados-nação.

A partir desse cenário, novos atores assumem para a condução de problemas ambientais e instaura-se uma governança mundial a fim de discutirem um consenso diante das drásticas questões ambientais. Motiva-se instrumentalização de um Desenvolvimento Sustentável que satisfaça apenas as necessidades das presentes e futuras gerações.

A noção de Desenvolvimento Sustentável tem um enfoque de conotação humana, todavia tem limite e, esses estão na natureza. Aqui é imperioso um equilíbrio ecológico, pois as necessidades humanas são dependentes de condições naturais a exemplo à água, ao ar puro, ao solo fértil e outros.

O Desenvolvimento Sustentável, como concepção, surgiu com a Primeira Conferência das Nações Unidas sobre o Meio Ambiente e Desenvolvimento em Estocolmo no ano 1972. A Organização das Nações Unidas (ONU) denominou a década de 1960 como a "Primeira Década das Nações Unidas" para o

\footnotetext{
5 Para Aquino e Zambam no sentido negativo da categoria tolerância, é descrito pelas ações indulgentes, condescendentes ao mal que se pratica na vida cotidiana. Trata-se da indiferença moral ou cegueira diante de valores ampliam e possibilitam a integração humana. ZAMBAM, Neuro José; AQUINO, Sérgio Ricardo de. Tolerância: Reflexões Filosóficas, Políticas e Jurídicas para o Século XXI. Revista da AJURIS - v. 42 - n. 137 - mar. 2015. p. 375. Disponível em: http://www.ajuris.org.br/OJS2/index.php/REVAJURIS/article/viewFile/389/323. Acesso em: 12 de julho de 2016.
} 
BORGES, Bruna Adeli. A materialização do desenvolvimento sustentável, o direito ao lazer e a ideia de democracia. Revista Eletrônica Direito e Política, Programa de Pós-Graduação Stricto Sensu em Ciência Jurídica da UNIVALI, Itajaí, v.11, n.3, 30 quadrimestre de 2016. Disponível em: www.univali.br/direitoepolitica - ISSN 1980-7791.

desenvolvimento, trazendo uma cooperação internacional que proporcionaria um crescimento econômico de modo a resolver os problemas dos países mais periféricos.

O termo Desenvolvimento Sustentável que vem definido no famoso relatório de 1987, Nosso Futuro Comum como: "desenvolvimento que respeita às necessidades da geração presente sem comprometer as necessidades das gerações futuras", abre espaços para minimizar a Sustentabilidade, bem como alastra a ideia de que se pode tudo ao mesmo tempo, crescimento econômico, meio ambiente saudável. Apresenta o relatório um primeiro passo, que segundo Novais $^{6}$, esse relatório destaca que o planeta é finito:

Reconhecer que o planeta é finito, não tem recursos
infindáveis; por isso, Humanidade precisa adotar formatos
de viver-padrões de produção e consumo - sustentáveis,
que não consumam mais recursos do que a biosfera
terrestre é capaz de repor; não comprometam o meio
ambiente, os muitos biomas do planeta, os seres vivis que
neles vivem, as cadeias alimentares e reprodutivas; não
degradem os seres humanos; além disso, os padrões de
viver não poderiam sacrificar recursos e comprometer os
direitos das futuras gerações. A participação ativa da sociedade é fundamental para que haja um Desenvolvimento Sustentável, tendo em vista que este mantém o progresso humano não apenas em alguns lugares, mas em todo do mundo, pois na medida em que o homem evolui surgem novas necessidades vitais ${ }^{7}$.

Os efeitos traduzidos pela compreensão da sustentabilidade se destinam tão somente aos humanos, apesar da intenção ao equilíbrio entre esses e a natureza. Por outro lado, novos tratados alternativos enfatizaram para as

${ }^{6}$ NOVAIS, Washington. Agenda 21: um novo modelo de civilização. In MELLO, Celso de Albuquerque. Anuário: Direito e Globalização, 1: a soberania. Rio Janeiro: Renovar, $1999, \mathrm{p}$. 324.

${ }^{7} \mathrm{O}$ modelo de desenvolvimento tem suas prioridades centralizadas no aumento de produção e do consumo, aprimoramento da tecnologia, fortalecimento das relações de mercado e no comércio internacional. Para realização desses objetivos utiliza-se recursos ambientais do Estado das pessoas e da sua força de trabalho e dos meios que têm à disposição. ZAMBAM, Neuro José. Amartya Sen, Liberdade, Justiça e Desenvolvimento Sustentável. Passo Fundo: IMED Editora, 2012, p. 124. 
BORGES, Bruna Adeli. A materialização do desenvolvimento sustentável, o direito ao lazer e a ideia de democracia. Revista Eletrônica Direito e Política, Programa de Pós-Graduação Stricto Sensu em Ciência Jurídica da UNIVALI, Itajaí, v.11, n.3, 30 quadrimestre de 2016. Disponível em: www.univali.br/direitoepolitica - ISSN 1980-7791.

preocupações e interconexões das questões ambientais, econômicas e sociais. A Declaração do Rio ${ }^{8}$ afirma que "[...] a fim de alcançar o desenvolvimento sustentável, a proteção ambiental deve ser parte integrante do processo de desenvolvimento e não pode ser considerada isoladamente deste", assim enseja para que haja desenvolvimento deve-se proteger o meio ambiente, visto que o homem é parte integrante do mundo natural.

No entanto, a Declaração do Rio reconheceu que o princípio da sustentabilidade não pode ser violado em relação ao desenvolvimento, pois o compromisso com a sustentabilidade vem a adotar a orientação da conservação e equilíbrio ao mundo natural compromisso que dialoga com as atuais e futuras gerações visando uma transformação das consciências que atuam com in(sustentabilidade). Trata-se, portanto, que a sustentabilidade ecológica, se torna vetor fundamental para se identificar responsabilidades comuns no tratamento e cuidado do mundo natural.

O fato é que o Desenvolvimento Sustentável deve ser entendido e executado a partir daquilo que enuncia no Princípio da Sustentabilidade, pois esse orienta a interpretação de normas jurídicas e estabelece uma compreensão da Justiça, Direitos Humanos e Soberania do Estado.

A relevância do desenvolvimento dirigido por uma sustentabilidade conduz à organização da economia, fortalece as Políticas Públicas, os recursos ambientais, bem como os recursos disponíveis. Estabelecendo assim, um aumento das capacidades humanas e das liberdades em geral, podendo funcionar por meio da promoção das liberdades integradas e interdependentes.

Em linhas mais precisas o Desenvolvimento Sustentável tem por teor a manutenção das fontes para produção e reprodução do homem e de suas atividades, neste sentido oportuniza uma relação de convivência entre homens e o ambiente para que todos possam desfrutar de recursos existentes e de

\footnotetext{
${ }^{8}$ BRASIL. Ministério do Meio Ambiente. Política de Educação Ambiental. A Carta da Terra. Disponível em: http://www.mma.gov.br/destaques/item/8071-carta-da-terra. Acesso dia 26 de novembro de 2015.
} 
BORGES, Bruna Adeli. A materialização do desenvolvimento sustentável, o direito ao lazer e a ideia de democracia. Revista Eletrônica Direito e Política, Programa de Pós-Graduação Stricto Sensu em Ciência Jurídica da UNIVALI, Itajaí, v.11, n.3, 30 quadrimestre de 2016. Disponível em: www.univali.br/direitoepolitica - ISSN 1980-7791.

oportunidades hoje á disposição. Para Neuro José Zambam "a relevância da fundamentação do direito ao Desenvolvimento Sustentável reflete os limites do atual modelo, tanto considerando o seu referencia teórico quanto sua efetivação e as consequências visíveis na quase totalidade das relações humanas e na vida social".

Para chegar ao equilíbrio, precisa-se de uma tomada de decisão na qual todos possam se envolver e cooperar com a implementação de ações transformadoras, em atitudes de cuidado e responsabilidade, a qual visa atender as necessidades de um grupo social no espaço que se ocupa e, em estabelecer formas para que a sociedade se organize a partir da observância das condições dos recursos naturais, tecnológicos e do bem-estar social. Neste sentido o Direito reivindica a integração de todos os seres como fator indispensável para a manutenção de um ambiente saudável.

O processo de intensificação da sociedade mundial produz uma série de modificações interligadas ao modelo do Estado moderno, a expansão das comunicações, do comércio, a preocupação ambiental e outros assuntos avançaram, gerando um espaço globalizado no meio de tantas transformações. Estabeleceu-se, no século XX o regime democrático e participativo da organização política em meio às inovações tecnológicas e científicas, relações entre comércio e capital, o crescimento das comunicações, uma melhor internacionalização entre os Estados, criando um ambiente próprio para o desenvolvimento democrático, bem como a concretização de direitos aos cidadãos.

Assim, os direitos do homem se modificou e continua a se modificar, com as mudanças das condições históricas, ou seja, dos carecimentos e dos interesses das classes no poder, dos meios disponíveis para a realização dos mesmos, das transformações técnicas.

\footnotetext{
${ }^{9}$ ZAMBAM, Neuro José. Desenvolvimento Sustentável: direito dos cidadãos e compromissos de todos. In: TRINDADE, André Karam; ESPINDOLA, Ângela Araújo da Silveira; BOFF, Salete Oro. Direito, Democracia e Sustentabilidade. Passo Fundo. IMED Editora, 2013, p. 93.
} 
BORGES, Bruna Adeli. A materialização do desenvolvimento sustentável, o direito ao lazer e a ideia de democracia. Revista Eletrônica Direito e Política, Programa de Pós-Graduação Stricto Sensu em Ciência Jurídica da UNIVALI, Itajaí, v.11, n.3, 30 quadrimestre de 2016. Disponível em: www.univali.br/direitoepolitica - ISSN 1980-7791.

Neste contexto, as garantias dos direitos fundamentais estabelecidos na Constituição Federal de 1988, ensejou um desenvolvimento como nunca visto num processo de expansão das liberdades em que as pessoas desfrutam, Amartya Sen argumenta que "expandir as liberdades que temos razão para valorizar não só torna nossa vida mais rica e mais desimpedida, mas também permite que sejamos seres sociais mais completos, pondo em prática nossas volições, interagindo com o mundo em que vivemos e influenciando esse mundo ${ }^{10 \prime \prime}$.

Para Amartya Sen a ideia de desenvolvimento ${ }^{11}$ está relacionada a um processo de expansão das liberdades em que as pessoas desfrutam e também atenta para os fins que são importantes como: tecnologia, informação, educação, lazer, etc. os quais desempenham um papel de extrema relevância no desenvolvimento dos indivíduos, não podendo associar este desenvolvimento somente a fatores como o crescimento do Produto Interno Bruto (PIB), ou a rendas pessoais, industrialização, tecnologia e seus avanços.

Neste sentido, a contribuição do crescimento econômico não é um fim em si mesmo, pois o desenvolvimento deve estar relacionado com o fortalecimento das liberdades dos indivíduos, o que contribuirá diretamente para que a expansão da liberdade seja fortalecida. Desta forma, o desenvolvimento depende de outras variáveis além da industrialização do progresso econômico e da modernização social, há os fatores de promoção de liberdades substantivas, quais sejam: as disposições sociais e econômicas, direitos civis e liberdade política.

O desafio da expansão das liberdades demanda um desenvolvimento de forma consciente voltada para as ações ${ }^{12}$ a serem realizadas numa forma dialógica na

\footnotetext{
${ }^{10}$ SEN, Amartya. Desenvolvimento como liberdade. Tradução Laura Teixeira Motta. São Paulo Companhia das Letras, p. 29.

${ }^{11} \mathrm{O}$ desenvolvimento tem de estar relacionado sobretudo com a melhora da vida que levamos e das liberdades que desfrutamos. Expandir as liberdades que temos razão para valorizar não só torna nossa vida mais rica e mais desimpedida, mas também permite que sejamos seres sociais mais completos, pondo em prática nossas volições, interagindo com o mundo em que vivemos e influenciamos esse mundo. SEN, Amartya. Desenvolvimento como liberdade, p. 29.
}

\footnotetext{
${ }^{12}$ Neste sentido, desenvolvimento sustentável, combate a pobreza erradicação da fome fim do trabalho escravo, políticas de saúde pública, promoção da paz e outros inúmeros exemplos pode
} 
BORGES, Bruna Adeli. A materialização do desenvolvimento sustentável, o direito ao lazer e a ideia de democracia. Revista Eletrônica Direito e Política, Programa de Pós-Graduação Stricto Sensu em Ciência Jurídica da UNIVALI, Itajaí, v.11, n.3, 30 quadrimestre de 2016. Disponível em: www.univali.br/direitoepolitica - ISSN 1980-7791.

elaboração e implementação das políticas públicas, possibilitando a sustentabilidade da vida econômica e social, superando a violação dos direitos humanos daqueles que se mantêm restritos numa profunda desigualdade.

O sistema político democrático leva a liberdade política, que por si fortalece as demais liberdades, assim podendo conduzir suas vidas, participando dos assuntos públicos de modo a alcançar um grau de liberdade consolidada. Nessa linha, Neuro José Zambam entende que "o homem tem o direito a um modelo de desenvolvimento no qual seja o agente principal ${ }^{13 \prime}$.

Deste modo, quando as pessoas conseguem realizar as suas necessidades básicas, podem participar da escolha social e da tomada de decisões públicas, na medida em que ampliam suas liberdades, contribui para o desenvolvimento e também são importantes para o fortalecimento da liberdade constitutiva. De maneira inversa, quando da limitação de uma liberdade específica, a exemplo da pobreza, contribui para privação de outras espécies de liberdade, gerando influências recíprocas. A despeito, a privação da liberdade vincula-se a carência de serviços públicos e assistenciais, a exemplo, da ausência de programas de saúde e de sistemas médicos e educacionais planejados ou de órgãos públicos eficazes para manter a sociedade organizada.

O cenário é de exercitar a liberdade permanente, de forma a concretizar os objetivos, o sentimento de poder de cada um dos cidadãos em constante ação como atores das ações, proporcionando para si e para a sociedade uma identidade.

A contribuição de Amartya Sen para o estudo do artigo faz compreender o fenômeno do desenvolvimento ${ }^{14}$, que através do conceito de liberdade pode-se

ser utilizados para demonstrar ações nas quais atores transnacionais/globais se inserem na tentativa de se fazer efetivo o ideal de direitos humanos. STAFFEN, Márcio Ricardo. Interfaces do Direito Global. Rio de Janeiro: Editora Lumen Juris, 2015.

\footnotetext{
${ }^{13}$ ZAMBAM, Neuro José. Desenvolvimento Sustentável: direito dos cidadãos e compromissos de todos. In: TRINDADE, André Karam; ESPINDOLA, Ângela Araújo da Silveira; BOFF, Salete Oro. Direito, Democracia e Sustentabilidade. Passo Fundo. IMED Editora, 2013, p, 94.

${ }^{14}$ A fundamentação do modelo de desenvolvimento sustentável tem como referência o valor moral substantivo da liberdade, precisa a atuação dos dirigentes sociais e das instituições políticas e
} 
BORGES, Bruna Adeli. A materialização do desenvolvimento sustentável, o direito ao lazer e a ideia de democracia. Revista Eletrônica Direito e Política, Programa de Pós-Graduação Stricto Sensu em Ciência Jurídica da UNIVALI, Itajaí, v.11, n.3, 30 quadrimestre de 2016. Disponível em: www.univali.br/direitoepolitica - ISSN 1980-7791.

ilustrar numa perspectiva o direito social ao lazer, que será o próximo tópico a ser estudado e cita-se como o estilo de vida das pessoas, a sua atitude de satisfação do indivíduo e o tempo disponível da pessoa com a sociedade, estes são os componentes constitutivos do desenvolvimento.

Por fim, o desenvolvimento consciente é sem dúvida a identidade da sociedade, num dinamismo onde a expansão das liberdades consolidadas superam a violação dos direitos humanos daqueles que se mantém em desigualdade e, assim contribuindo para as condições de justiça, dotados de validade universal.

O estudo desta temática analisou o desenvolvimento sustentável como um valor moral e como um referencial decisivo para a construção da justiça, trazendo juntamente o conceito de liberdade na ideia de Amartya Sen. O próximo tópico abordará o direito social ao lazer, trazendo seu conteúdo e seus principais referenciais teóricos.

\section{O DIREITO SOCIAL AO LAZER}

O lazer, como fator de desenvolvimento humano é fundamental para todos os seres é resultado da experiência cultural construída, é um dos meios pelo qual a pessoa pode se desenvolver existencialmente como ser humano e cidadão responsável de uma comunidade, regrando sua vida com atitudes e tempos que possam contribuir para o aumento de suas capacidades e habilidades, tendo como base o aproveitamento das diversas experiências do cotidiano, não somente para si, mas também, para as demais pessoas ao seu redor. Por isso

econômicas com o objetivo de estruturar o modelo de desenvolvimento comprometido com a garantia, promoção e efetivação das liberdades substantivas. O modelo de desenvolvimento possui legitimidade na medida em que tem capacidade de integrar as pessoas, as instituições e os demais agentes sociais na busca da superação da desigualdade, analfabetismo, nos governos ditatoriais e na estruturação de uma estrutura nas relações políticas que preserve e aprimore a democracia. ZAMBAM, Neuro José. Amartya Sen, Liberdade, Justiça e Desenvolvimento Sustentável, p. 125. 
BORGES, Bruna Adeli. A materialização do desenvolvimento sustentável, o direito ao lazer e a ideia de democracia. Revista Eletrônica Direito e Política, Programa de Pós-Graduação Stricto Sensu em Ciência Jurídica da UNIVALI, Itajaí, v.11, n.3, 30 quadrimestre de 2016. Disponível em: www.univali.br/direitoepolitica - ISSN 1980-7791.

que o lazer estabelecido na Constituição Federal de 1988 e tipificado no artigo $6^{\circ}$ "caput" juntamente, com outros direitos sociais é fundamental para todos os homens, é através desse direito que indivíduo pode entregar-se de livre vontade, seja para repousar, seja para divertir-se, recrear-se e entreter-se ou, ainda para desenvolver sua informação ou formação desinteressada, sua participação social voluntária ou a sua livre capacidade criadora, após livrar-se ou desembaraçar-se das obrigações profissionais, familiares e sociais ${ }^{15}$.

O lazer, como desenvolvimento da personalidade, tem a ver com a disponibilidade participativa e atitudes conscientizadas, criativas, enriquecedoras, em suma, preponderância do viés humanista do individuo, sendo necessário e fundamental para satisfazer todos os seres. Como parte de tudo isso, cabe ao Poder Público fornecer e proporcionar esse momento de lazer para as pessoas como forma de divertimento, desconcentração, motivando as atividades culturais, entre outras, para toda a população ${ }^{16}$.

Desse modo, Poder Público através das políticas públicas deve assegurar a distribuição e a coordenação do atendimento de aspirações individuais e sociais dentro de uma esfera coletiva. O Poder Público não pode ser omisso no que se refere à promoção do lazer, ele tem o dever de elaborar políticas que propiciem as pessoas maior acesso à cultura e ao atendimento eis que o Estado deve gerar projeto de democratização para aproximar a maior quantidade de pessoas da cultura.

Assim, o direito ao lazer é parte integrante da vida do homem e, portanto, estabelecido no texto constitucional, deve ser efetivado no Estado Democrático de Direito. Cabe ressaltar que é de fundamental importância que o Estado proveja do atendimento desse referido direito atendendo à toda população.

Assim, o lazer deve ser entendido como uma necessidade social, por isso, sendo também motivo de intervenção política e argumento para o crescimento de ações

\footnotetext{
${ }^{15}$ MARCELLINO, Nelson Carvalho. Lazer e humanização. 3a ed. São Paulo: Papirus, 1983, p. 25.

${ }^{16}$ CHEMIN, Beatris Francisca. Políticas Públicas de Lazer: o papel dos Municípios na sua implementação. Curitiba: Juruá, 2007, p. 58.
} 
BORGES, Bruna Adeli. A materialização do desenvolvimento sustentável, o direito ao lazer e a ideia de democracia. Revista Eletrônica Direito e Política, Programa de Pós-Graduação Stricto Sensu em Ciência Jurídica da UNIVALI, Itajaí, v.11, n.3, 30 quadrimestre de 2016. Disponível em: www.univali.br/direitoepolitica - ISSN 1980-7791.

governamentais direcionadas para esse mesmo sentido ${ }^{17}$. Dessa forma, é fundamental que o direito ao lazer seja um componente indispensável na construção de qualidade de vida para a população como um todo. O aumento da participação popular em atividades, ou seja, na vivência do lazer é essencial para o desenvolvimento humano e busca a instauração de uma nova ordem social com mudança moral e cultural para que se possa difundir o direito ao lazer e, para tanto há necessidade urgente de políticas públicas mas efetivas para sua concretização ${ }^{18}$.

O lazer, por ser consagrado na Constituição Federal de 1988 representa um avanço quanto ao seu reconhecimento como um dos direito sociais a serem garantidos e, por conseguinte fundamental ao homem, se caracteriza como uma liberdade positiva que deve ser observada pelo Poder Público. Em sendo concretizado, haveria melhoria na qualidade de vida das pessoas e maior efetivação da igualdade social material. No entanto, a efetivação do direito ao lazer requer a união de diversas políticas públicas em áreas que se encontram juntamente ao lazer e que objetivam também a busca do bem-estar social para todos. Esse reconhecimento constitucional evidencia que o direito ao lazer é necessário e é dever do Estado proporcionar tal direito por meio de políticas públicas e com a participação de todos os setores da sociedade ${ }^{19}$.

O lazer ${ }^{20}$ como fundamental é um campo de atividade de estreita ligação com as demais áreas da atuação humana. Isto, pois, engloba atividades anti-estresse e

\footnotetext{
${ }^{17}$ CHEMIN, Beatris Francisca. Políticas Públicas de Lazer: o papel dos Municípios na sua implementação, p. 82.
}

${ }^{18}$ CHEMIN, Beatris Francisca. Políticas Públicas de Lazer: o papel dos Municípios na sua implementação, p. 82-83.

${ }^{19}$ GOMES, Cristianne; OSORIO, Esperanza; PINTO, Leila; ELIZALDE, Rodrigo. Organizadores. Lazer na América Latina. Belo Horizonte: Editora UFMG, 2009, p. 78.

20 O lazer como fator de desenvolvimento humano, como resultado da experiência cultural construída, é um dos meios pelo qual a pessoa pode se desenvolver existencialmente como ser humano e cidadão responsável de uma comunidade, regrando sua vida com atitudes e tempos que possam contribuir para um aumento em grau ótimo de suas capacidades e habilidades, tendo como base o desenvolvimento qualitativo e quantitativo das diversas experiências do cotidiano, não só para si, mas também para as demais pessoas ao seu redor. Enfim, lazer como desenvolvimento da personalidade tem a ver com disponibilidade participativa e atitudes conscientizadas, criativas, 
BORGES, Bruna Adeli. A materialização do desenvolvimento sustentável, o direito ao lazer e a ideia de democracia. Revista Eletrônica Direito e Política, Programa de Pós-Graduação Stricto Sensu em Ciência Jurídica da UNIVALI, Itajaí, v.11, n.3, 30 quadrimestre de 2016. Disponível em: www.univali.br/direitoepolitica - ISSN 1980-7791.

tempo de descanso, repouso, sendo associado popularmente além do tempo livre do trabalho ${ }^{21}$, do estilo de vida, a atividades recreativas e culturais, atividades como teatro, cinema, exposições, esportes, entretenimento, ou a manifestação ao ar livre e de conteúdo recreativo.

O lazer dentro da diversidade de interpretações existentes pode ser compreendido basicamente, como a cultura vista de forma abrangente. A ideia de lazer é identificada por meio de duas grandes linhas de pensamento: a primeira como estilo de vida das pessoas, a sua atitude de satisfação, de prazer, de bem estar diante das experiências da vida; segunda, como tempo disponível que a pessoa tem a livre escolha ou atividades em geral ${ }^{22}$ incluídas (familiar, sociais, escolares, etc.) e do próprio trabalho como objetivos econômicos.

Pode-se afirmar que um trabalho empobrecedor está ligado a um lazer também empobrecedor e vice-versa. O sentido da vida não pode ser buscado, como muitas vezes somos levados a crer, apenas num final de semana, ou numa viagem, embora essas ocasiões possam ser consideradas como possibilidade de felicidade e formas de resistência para o dia-a-dia. A admissão da importância do lazer na vida moderna, significa considerá-lo a um tempo privilegiado para a vivência de valores que contribuam para mudanças de ordem moral e cultural.

enriquecedoras - em suma, preponderância do viés humanista do indivíduo. CHEMIN, Beatris Francisca. Políticas Públicas de Lazer: o papel dos Municípios na sua implementação, p. 58.

${ }^{21} \mathrm{O}$ lazer considerado como "atitude" será caracterizado pelo tipo de relação verificada entre o sujeito e a experiência vivida, basicamente, a satisfação provocada pela atividade. Assim, qualquer situação poderá se constituir em oportunidades para a prática de lazer - até mesmo o trabalho. Entretanto, tendo em vista o caráter das ocupações profissionais, na sociedade contemporânea, pode-se distinguir um componente de obrigação marcante, que faz parte também de outras esferas da vida social. Mesmo quando a pessoa não sente satisfação, muitas vezes é obrigada a desenvolver atividades profissionais ou familiares, por exemplo. MARCELLINO, Nelson Carvalho. Lazer e educação. $3^{a}$ ed. São Paulo: Papirus, 1995, p. 29.

22 No lazer, os valores do individualismo devem ser igualmente reconsiderados num sentido oposto: jogos, viagens, relações afetivas ou estudos pessoais, ontem considerados por muito como uma perda de tempo, uma diversão suspeita, ou um atentado aos deveres familiais, sociais, tendem hoje, em certas condições ainda tênues e variáveis em cada situação, a se tornarem novas exigências da pessoa. Neste tempo prescrito pela nova norma social, nem a eficiência técnica, nem a utilidade social, nem o engajamento espiritual ou político constituem a finalidade do indivíduo, mas sim a realização e a expressão de sim mesmo. DUMAZEDIER, Jofre. Sociologia empírica do lazer. Tradução Silvia Mazza. São Paulo: Perspectiva, 1999, p. 60. 
BORGES, Bruna Adeli. A materialização do desenvolvimento sustentável, o direito ao lazer e a ideia de democracia. Revista Eletrônica Direito e Política, Programa de Pós-Graduação Stricto Sensu em Ciência Jurídica da UNIVALI, Itajaí, v.11, n.3, 30 quadrimestre de 2016. Disponível em: www.univali.br/direitoepolitica - ISSN 1980-7791.

Mudanças necessárias para a implantação de uma nova ordem social e na busca pela vivência do tempo de lazer ${ }^{23}$.

Dessa forma, o direito ao lazer pode ser tido como direito fundamental do homem de se desenvolver como ser humano dotado de razão e desejo, na busca de sua elevação física, psíquica, social e espiritual, estimulando e aprimorando seus talentos e capacidades no interesse e que bem lhe prouver ${ }^{24}$.

É possível afirmar que a sustentabilidade é vista como base do processo de consolidação dos direitos fundamentais, em especial do direito ao lazer, que pode ser visto como necessidade biológica, ou seja, tempo ${ }^{25}$ que o ser humano restabelece suas energias, ou seja, o lazer é tido como uma necessidade importante do homem em todos os tempos e lugares que varia apenas de intensidade e de forma de expressão, segundo o contexto físico, socioeconômico e político social de cada grupo ${ }^{26}$.

O lazer do ponto de vista social ${ }^{27}$ é aquele em que se tem um tempo livre necessário para viabilizar a convivência social nas relações familiares e privadas. Neste sentido, pode-se afirmar que o lazer não é uma categoria, porém um estilo 23 MARCELLINO, Nelson Carvalho. Estudo do lazer: uma introdução. São Paulo: Autores
Associados, 2000, p. 16.

24 CHEMIN, Beatris Francisca. Políticas Públicas de Lazer: o papel dos Municípios na sua implementação, p. 55.

25 Apesar da polêmica sobre o conceito, a tendência que se verifica na atualidade, entre os estudiosos do lazer, é no sentido de considerá-lo tendo em visa dois aspectos - tempo e atitude. Portanto, como uma atividade de escolha individual, praticada no tempo disponível e que proporcione determinados efeitos, como o descanso físico ou mental, o divertimento e o desenvolvimento da personalidade e da sociabilidade. Entretanto dessa forma, o conteúdo das atividades de lazer é bastante amplo, abrangendo interesses variados. MARCELLINO, Nelson Carvalho. Lazer e educação, p. 31.

26 MARCELLINO, Nelson Carvalho. Lazer e educação, p. 33-34.

27 A respeito deste fator social, a prática de lazer tem de vir acompanhada de uma boa conscientização de sua importância para o desenvolvimento humano, para que não esteja a serviço apenas do mundo do trabalho, procurando evitar a homogeneização das formas de lazer, das atividades impostas pela sociedade consumista, impregnadas pela mídia de massa, finde por regrar a vida do trabalhador, de maneira a enquadrá-lo num esquema predeterminado e que reproduza a influência da noção de trabalho nos demais setores da vida civil. CHEMIN, Beatris Francisca. Políticas Públicas de Lazer: o papel dos Municípios na sua implementação, p. 56. 
BORGES, Bruna Adeli. A materialização do desenvolvimento sustentável, o direito ao lazer e a ideia de democracia. Revista Eletrônica Direito e Política, Programa de Pós-Graduação Stricto Sensu em Ciência Jurídica da UNIVALI, Itajaí, v.11, n.3, $3^{0}$ quadrimestre de 2016. Disponível em: www.univali.br/direitoepolitica - ISSN 1980-7791.

de comportamento, podendo ser encontrado em não importa qual atividade, pode-se trabalhar com música, estudar brincando, lavar a louça ouvindo rádio. Toda a atividade pode pois vir a ser um lazer ${ }^{28}$.

Todavia, o lazer ${ }^{29}$ pode ser visto no sentido existencial em que a pessoa tem acesso aos bens culturais variados e de todas as formas que incrementassem valor ao ser humano, no sentido de desenvolvimento e crescimento individual. Nas palavras de José Afonso da Silva lazer é a entrega à ociosidade repousante. Recreação é a entrega ao divertimento, ao esporte, ao brinquedo. Ambos se destinam a refazer as forças depois da labuta diária e semanal. Ambos requerem lugares apropriados, tranquilos, repletos de folguedos e alegrias ${ }^{30}$.

Neste sentido, o direito ao lazer vem sendo construído pela compreensão de sentidos e significados historicamente constituídos em práticas culturais cotidianas, sociais e políticas. Desafio que permite identificar fundamentos, valores, dificuldades e conquistas que marcam o percurso desse fenômeno em toda a sociedade. O lazer procura ganhar (re)conhecimento e é identificado como instrumento e/ou objeto para melhoria da qualidade de vida da população, para a auto-humanização, para o prazer, para diversão, recreação, entretenimento, principalmente, proporcionando o bem-estar a todos.

No entanto, o reconhecimento do lazer como um direito de cidadania deve ser interpretado como uma grande conquista, pois sua presença em documentos legais nos permite reivindicar do poder público, da inciativa privada e demais

\footnotetext{
${ }^{28}$ DUMAZEDIER, Jofre. Sociologia empírica do lazer, p. 60.

29 O lazer concerne a um conjunto mais ou menos estruturado de atividades com respeito às necessidades do corpo e do espírito dos interessados: lazeres físicos, práticos, artísticos, intelectuais, sociais, dentro dos limites do condicionamento econômico social, político e cultural de cada sociedade. DUMAZEDIER, Jofre. Sociologia empírica do lazer, p. 92.
}

30 SILVA, José Afonso. Comentário contextual à Constituição. São Paulo: Malheiros, 2005, p.186. 
BORGES, Bruna Adeli. A materialização do desenvolvimento sustentável, o direito ao lazer e a ideia de democracia. Revista Eletrônica Direito e Política, Programa de Pós-Graduação Stricto Sensu em Ciência Jurídica da UNIVALI, Itajaí, v.11, n.3, 30 quadrimestre de 2016. Disponível em: www.univali.br/direitoepolitica - ISSN 1980-7791.

setores da sociedade os meios para concretizá-los e efetivá-los na vida cotidiana de toda a população ${ }^{31}$.

A construção do lazer aqui exposto, não se esgota na Constituição e na discussão desenvolvida no país referente a sua concretização e efetivação, o lazer está relacionado, também, com a humanização e democratização do acesso dos sujeitos de todas as idades, gêneros, etnias e camadas sociais, às oportunidades de lazer disponíveis requer políticas públicas postas em ação que o Brasil precisa adquirir $^{32}$.

Os argumentos apresentados nesta pesquisa destaca o lazer ${ }^{33}$ como um valor básico das sociedades democráticas, as quais buscam a garantia da igualdade de direitos, a liberdade e a valorização da diversidade. Com a promulgação da Constituição Federal de 1988, mas avançada no que se refere à ampliação dos direitos sociais a toda população brasileira, incluindo em especial o direito ao lazer em que o Estado deve proporcionar meios efetivos à sua concretização. Porém, a ideia de democracia que será analisada no próximo tópico é fundamental para que haja políticas públicas efetivas voltadas para busca do lazer.

\footnotetext{
${ }^{31}$ GOMES, Cristianne; OSORIO, Esperanza; PINTO, Leila; ELIZALDE, Rodrigo. Organizadores. Lazer na América Latina, p. 78.

32 GOMES, Cristianne; OSORIO, Esperanza; PINTO, Leila; ELIZALDE, Rodrigo. Organizadores. Lazer na América Latina, p. 80-81.

33 O lazer é uma experiência que se renova nos contrastes da vida cotidiana, concorre para que homens e mulheres se humanizem e se reconciliem com a natureza, podendo contribuir para melhoria da qualidade de vida de todos. GOMES, Cristianne; OSORIO, Esperanza; PINTO, Leila; ELIZALDE, Rodrigo. Organizadores. Lazer na América Latina, p. 110. Em complemento: STAFFEN, Márcio Ricardo. Direito Global: Humanismo e Direitos Humanos. Revista do Mestrado em Direito da Universidade Católica de Brasília, v. 10, n. 1, p. 178-208, jan./jun. 2016.
} 
BORGES, Bruna Adeli. A materialização do desenvolvimento sustentável, o direito ao lazer e a ideia de democracia. Revista Eletrônica Direito e Política, Programa de Pós-Graduação Stricto Sensu em Ciência Jurídica da UNIVALI, Itajaí, v.11, n.3, 30 quadrimestre de 2016. Disponível em: www.univali.br/direitoepolitica - ISSN 1980-7791.

\section{A IDEIA DE DEMOCRACIA}

A contemporaneidade deve ser encarada como um ponto de referência decisiva, pois inaugura uma nova formação para a sociedade. Sem dúvida, a característica fundamental desta modernidade é o advento da revolução democrática ${ }^{34}$, que está na origem dos novos tipos de constituição e dinâmica social. A essência da Democracia funda-se na ideia de que a decisão deve abranger a escolha da maioria, de maneira a cumprir a função de ser modelo de governo eficiente para o povo. Assim, em um regime democrático, cabe ao povo tomar as decisões políticas de interesse relevante, de forma direta ou indireta, por meio de representantes ${ }^{35}$ eleitos.

A democracia consiste no direito de todos participarem das decisões que repercutem em todos os âmbitos de convívio, inclusive, da atuação do governo. Isto, de duas formas principais: a primeira, através da participação direta, com opinião e efetividade para suas decisões ${ }^{36}$; a segunda, indireta, através de representante escolhidos pelos cidadãos. Segundo Neuro José Zambam ${ }^{37}$ :

\footnotetext{
${ }^{34}$ Quando, recentemente, perguntaram a Amartya Sen qual tinha sido o acontecimento mais importante do século XX, ele respondeu sem hesitação: a emergência da democracia. Com uma visão mais pessimista do século XX também Immanuel Wallerstein se perguntava recentemente como democracia tinha passado de uma aspiração revolucionária do século XIX a um slogan adotado universalmente mais vazio de conteúdo do século XX. Estas duas posições, apesar de muito divergentes convergem na constatação de que a democracia assumiu um lugar central no campo político durante o século XX. SANTOS, Boaventura de Souza. Democratizar a democracia: os caminhos da democracia participativa. Rio de Janeiro: Civilização Brasileira, 2002, p. 39.

35 A legitimidade da democracia representativa alcançará maior reconhecimento quanto mais a população tenha condições e instrumentos de interagir com o sistema. A inclusão de outros instrumentos de consulta para temas relevantes necessitam de aprimoramento e da prática dos mecanismos e dispositivos com igual tradição, por exemplo, plebiscito, o referendo. A ampliação dos mecanismos de participação e decisão sinaliza para avaliação da consistência e legitimidade de uma sociedade democrática. ZAMBAM, Neuro José. A democracia contemporânea: entre a cruz e a espada. In: TRINDADE, André Karam; ESPINDOLA, Ângela Araújo da Silveira; BOFF, Salete Oro. Direito, Democracia e Sustentabilidade. Anuário do Programa de Pós-Graduação Stricto Sensu em Direito da Faculdade IMED. Passo Fundo. IMED Editora, 2014, p. 161.
}

${ }^{36}$ No direito brasileiro, o grande exemplo é o elenco do artigo 14 da Constituição Federal, pois prevê a participação direta por meio de "iniciativa popular".

37 ZAMBAM, Neuro José. Amartya Sen, Liberdade, Justiça e Desenvolvimento Sustentável. Passo Fundo: IMED Editora, 2012, p. 207. 
BORGES, Bruna Adeli. A materialização do desenvolvimento sustentável, o direito ao lazer e a ideia de democracia. Revista Eletrônica Direito e Política, Programa de Pós-Graduação Stricto Sensu em Ciência Jurídica da UNIVALI, Itajaí, v.11, n.3, 30 quadrimestre de 2016. Disponível em: www.univali.br/direitoepolitica - ISSN 1980-7791.

A democracia é o sistema que possui as melhores estruturas e os meios necessários e suficientes para a realização das metas mais importantes da existência humana. A democracia possibilita para o conjunto da sociedade uma dinâmica especial que garante o exercício da liberdade, simboliza na discussão pública como condição indispensável para todo seu processo de organização e para as necessárias opções que caracterizam um modelo de desenvolvimento sustentável. O debate público envolve as pessoas, avalia interesses, torna explícitas as escolhas e de forma integrada dinamiza o conjunto das relações sociais.

A gênese da democracia ${ }^{38}$ é tão antiga quando a própria organização do homem em sociedade. Assim, nasceu, ao mesmo tempo, na maioria das organizações humanas rudimentares, como aglomerados familiares e tribos primitivas, pois, nestes locais, as decisões eram tomadas pelo líder, todavia, partiam de uma discussão prévia, em rodas de conversa, entre os membros do convívio ${ }^{39}$.

A democracia, embora antiga, só teve conceito, formulado e assentado, há pouco mais de vinte e cinco séculos. Assim, no desenrolar do tempo, vem se aprimorando, especialmente, do ponto de vista da prática social. Na verdade, as modificações do Estado, ao longo dos anos, trouxeram ao homem moderno ${ }^{40} \mathrm{o}$

\footnotetext{
38 Preliminarmente, cabe salientar que o único modo de se chegar a um acordo quando se fala de democracia, entendida como contraposta a todas as formas de governo autocrático, é o de considerá-la caracterizada por um conjunto de regras (primárias ou fundamentais) que estabelecem quem está autorizado a tomar as decisões coletivas e com quais procedimentos. Todo grupo social está obrigado a tomar decisões vinculatórias para todos os seus membros com o objetivo de prover a própria sobrevivência, tanto interna como externamente. Mas até mesmo as decisões de grupo são tomadas por indivíduos (o grupo como tal não decide). Por isto, para que uma decisão tomada por indivíduos (um, poucos, muitos, todos) possa ser aceita como decisão coletiva é preciso que seja tomada com base em regras (não importa se escritas ou consuetudinárias) que estabeleçam quais são os indivíduos autorizados a tomar as decisões vinculatórias para todos os membros do grupo, e à base de quais procedimentos. No que diz respeito aos sujeitos chamados a tomar (ou a colaborar para a tomada de) decisões coletivas, um regime democrático caracteriza-se por atribuir este poder (que estando autorizado pela lei fundamental tornase um direito) a um número muito elevado de membros do grupo. Percebo que "número muito elevado" é uma expressão vaga. No entanto, os discursos políticos inscrevem-se no universo do "aproximadamente" e do "na maior parte das vezes" e, além disto, é impossível dizer "todos" porque mesmo no mais perfeito regime democrático não votam os indivíduos que não atingiram uma certa idade." BOBBIO, Noberto. O futuro da democracia; uma defesa das regras do jogo. Trad. Marco Aurélio Nogueira. Rio de Janeiro: Paz e Terra, 1986, p.18-19
}

${ }^{39}$ DAHL, Robert. Sobre a democracia. Brasília: UnB, 2009, p. 19-20.

40 "O homem do Estado moderno é homem apenas acessoriamente político, ainda nas democracias mais aprimoradas onde todo um sistema de garantias jurídicas e sociais fazem efetiva e válida a sua condição de "sujeito" e não apenas "objeto" da organização política." BONAVIDES, Paulo. Ciência Política. São Paulo: Editora Malheiros, 10ª Ed, 2000, p. 352. 
BORGES, Bruna Adeli. A materialização do desenvolvimento sustentável, o direito ao lazer e a ideia de democracia. Revista Eletrônica Direito e Política, Programa de Pós-Graduação Stricto Sensu em Ciência Jurídica da UNIVALI, Itajaí, v.11, n.3, 30 quadrimestre de 2016. Disponível em: www.univali.br/direitoepolitica - ISSN 1980-7791.

viés democrático. Sendo assim, naturalmente, adveio uma série de questionamentos, como por exemplo, o exercício da democracia associado ao desenvolvimento tecnológico. Isto, essencialmente, em função da distância fática no relacionamento entre os atores sociais e o governo, pois, não raro, há dissonância entre participação e permissão democrática.

No entanto, foi com a Declaração Universal dos Direitos do Homem, de 1948, houve um avanço na efetivação da Democracia mundial, afirmando que esta Democracia seria o único regime político compatível, com o pleno respeito aos direitos humanos. Desta forma, reconheceram-se os direitos humanos como um tema global e legitimado frente a uma preocupação internacional com a sua promoção e proteção, afastando a objeção de que trata este assunto ser de única e exclusiva competência dos Estados. Assim, a Democracia passou a compor a relações internacionais, tornando-se uma questão de interesse global.

A Democracia não pode existir desvinculada dos direitos humanos. A ausência destes direitos inviabiliza o exercício dos demais, pois "sem direitos do homem reconhecidos e protegidos, não há Democracia; sem Democracia não existem as condições mínimas para solução pacífica dos conflitos ${ }^{41 "}$.

Destaca-se que a Democracia requer uma estabilidade e segurança, verdadeiramente um regime que garanta o apoio da sociedade, não devendo fragmentar os direitos humanos e resguardando a dignidade de todos. O poder político dos direitos humanos demanda primeiro, a convicção de que uma sociedade de direitos cada vez mais ampliados e efetivados no cotidiano dos cidadãos é garantia de estabilidade social e política ${ }^{42}$. Rawls ${ }^{43}$ defende a possibilidade de se atingir a paz democrática, expondo a função do pluralismo

\footnotetext{
41 BOBBIO, Norberto; MATTEUCCI, Nicola; PASQUINO, Gianfranco. Dicionário de Política. Brasília: UNB, 1992, p.1

${ }^{42}$ ZAMBAM, Neuro José. A democracia contemporânea: entre a cruz e a espada. In: TRINDADE, André Karam; ESPINDOLA, Ângela Araújo da Silveira; BOFF, Salete Oro. Direito, Democracia e Sustentabilidade. Anuário do Programa de Pós-Graduação Stricto Sensu em Direito da Faculdade IMED. Passo Fundo. IMED Editora, 2014, p. 163

43 RAWLS, John. O direito dos povos. Tradução Luís Carlos Borges. São Paulo: Martins Fontes, 2001, p. 13.
} 
BORGES, Bruna Adeli. A materialização do desenvolvimento sustentável, o direito ao lazer e a ideia de democracia. Revista Eletrônica Direito e Política, Programa de Pós-Graduação Stricto Sensu em Ciência Jurídica da UNIVALI, Itajaí, v.11, n.3, 30 quadrimestre de 2016. Disponível em: www.univali.br/direitoepolitica - ISSN 1980-7791.

razoável para estabelecer uma base comum em uma sociedade dos povos ${ }^{44}$, na qual seja possível perceber diferenças razoáveis de culturas diferentes.

Por certo, em uma Democracia, não se pode pensar em consensos absolutos e nem mesmo em apelos ao antipolítico: isso seria fatal para o processo democrático. Fica claramente delimitado que a Democracia desvela as diferenças inerentes às relações humanas. Logo, os antagonismos precisam ter espaço na esfera política, pois as identificações oriundas de questões ideológicas, étnicas, religiosas, entre outras, podem determinar as diferenças políticas, influenciando o processo democrático.

Dessa forma, o sujeito encontra-se atualmente inserido em um contexto histórico de transformação ${ }^{45}$, estando diante de múltiplas alternativas a respeito das suas preferências e dos seus interesses políticos. A Democracia mantém sua hegemonia, embora seja uma forma de governo bastante antiga, com alteração nos seus modelos para adaptar-se aos novos momentos históricos vivenciados pelo cidadão.

Deste modo, a democracia, como integrante do Estado, especialmente, como ordem política da sociedade, é conhecida desde a antiguidade. Contudo, foi nos tempos modernos e contemporâneos que se alastrou. Neste sentido, é possível se atribuir, grande parte da disseminação deste ideal, a Montesquieu, que a trouxe, aliada ao seu entendimento de Estado, na obra o "Espírito das Leis ${ }^{46 ",}$

\footnotetext{
44 Rawls concebe a Sociedade dos Povos com caráter liberal, alegando que as instituições liberais são as mais adequadas para a Sociedade dos Povos como um todo. Porém, não quer impor tal concepção às outras sociedades, defendendo a elaboração de ideais e princípios da política exterior de um povo liberal razoavelmente justo. Basta que os princípios exteriores, formulados a partir de um ponto de vista liberal, sejam razoáveis de um ponto de vista não-liberal decente. Trata-se, portanto, de uma teoria liberal que pode ser aceita por povos não-liberais. RAWLS, John. O direito dos povos, p. 26.
}

45 O multiculturalismo supõe as condições para a organização de um modelo de relacionamento que contempla as pessoas com suas características, interesses necessidades, os limites dos recursos disponíveis e o compromisso com as condições de existência das futuras gerações. A importância da reflexão sobre a formação cultural e suas características visa um processo de valorização e aprimoramento dos valores essências que contribuem para a cooperação social entre as quase se destacam a tolerância, o respeito e a liberdade. ZAMBAM, Neuro José. Amartya Sen, Liberdade, Justiça e Desenvolvimento Sustentável, p. 203.

${ }^{46}$ MONTESQUIEU, Charles de Secondant. O espírito das leis. São Paulo: Martins Fontes, 2000. p. 207. 
BORGES, Bruna Adeli. A materialização do desenvolvimento sustentável, o direito ao lazer e a ideia de democracia. Revista Eletrônica Direito e Política, Programa de Pós-Graduação Stricto Sensu em Ciência Jurídica da UNIVALI, Itajaí, v.11, n.3, 30 quadrimestre de 2016. Disponível em: www.univali.br/direitoepolitica - ISSN 1980-7791.

uma das mais difundidas da filosofia de social. Assim, expandiu-se a alusão à democracia como pautada num governo composto por representantes escolhidos pelo povo, onde a vida em sociedade pode ser mais harmônica em razão dos rumos sociais serem determinados por todos os participantes. A democracia, tal como surgiu e se estruturou, deve ser entendida como um conjunto de ferramentas de redes cidadãs, destinadas à população em geral, com finalidade, justamente, coletiva.

Na sequência, ao tratar da ideia de democracia, Montesquieu traz dois fatores importantes: liberdade e igualdade ${ }^{47}$. Desta liberdade e igualdade, adotadas por Montesquieu, o povo é chamado para decidir questões de grande relevância através de seus representantes eleitos para garantir que o homem tenha o direito de viver de forma igualitária.

Assim, com base nos ideais de liberdade e igualdade, no mundo mais recente, surgiu a democracia participativa. Esta se baseia numa escolha consciente dos cidadãos por autonomia, tendo como alicerce a participação ativa.

Assim, a democracia tem as condições para atuar na prevenção de graves crises que possam ocorrer tanto na área das relações econômicas, representada pela satisfação básica de sobrevivência, quanto na diplomacia internacional, especificamente na prevenção de conflitos armados ou pela imposição de interesses corporativos. O investimento em políticas públicas de bem-estar por meio de programas sociais é um instrumento decisivo e eficaz para mudança social. A preocupação com a efetivação das políticas de bem-estar é um claro exemplo de como a democracia pode chegar a todas as pessoas especialmente

\footnotetext{
${ }^{47}$ A igualdade ela deve existir mas não de forma excessiva, pois se todos são iguais, estão em mesmas condições, um vai querer mandar no outro e este não vai querer se submeter, e nenhum poder de comando irá existir. O outro cuidado que também deve-se ter é para que a igualdade não deixe de existir ou seja reduzida, porque daí não vai mais ter democracia. Já a liberdade é o direito do cidadão fazer tudo o que a lei permite, se fizer o que a lei não permite a liberdade não existe também. FONTANA, Odisséia Aparecida Paludo; MEZZAROBA, Orides. Accountability como mecanismo para o exercício da democracia inclusiva através das atribuições do Conselho Nacional de Justiça. In. ROVER, Aires José; GALINDO, Fernando; MEZZAROBA, Orides. Direito, Governança e Tecnologia: princípios, políticas e normas do Brasil e da Espanha. Florianópolis: Conceito Editorial, 2014, p. 332.
} 
BORGES, Bruna Adeli. A materialização do desenvolvimento sustentável, o direito ao lazer e a ideia de democracia. Revista Eletrônica Direito e Política, Programa de Pós-Graduação Stricto Sensu em Ciência Jurídica da UNIVALI, Itajaí, v.11, n.3, 30 quadrimestre de 2016. Disponível em: www.univali.br/direitoepolitica - ISSN 1980-7791.

às mais pobres e resgatar desde a autoestima até expressivos meios de participação social ${ }^{48}$.

As melhorias na condição de vida das pessoas são um componente importante das liberdades substantivas, porque resgatam a condição de agente social, contribuindo para a diminuição das desigualdades. A democracia assegura o vigor e o dinamismo de sua atuação na capacidade de complementar as variadas formas de manifestação dos interesses que integram a dinâmica da sociedade, preocupa-se com o atendimento das necessidades imediatas. A democracia em conexão com o princípio da sustentabilidade atende às necessidades econômicas ao mesmo tempo que garante o desenvolvimento das liberdades substantivas ${ }^{49}$.

Por fim, nos regimes democráticos sempre se deve buscar a melhoria da ordem social. A história demostra que esta ordem é fruto do esforço da vontade e da atitude do homem. Assim, ser um cidadão dotado de possibilidades para contribuir com a concretização de um regime democrático fortalece e incentivar os homens a viver e atuar no espaço público, agindo continuamente para incitar uma evolução sadia e que respeite os ditames da Democracia, fundamental para uma vida digna no seio da sociedade.

\section{CONSIDERAÇÕES FINAIS}

O Desenvolvimento Sustentável tem por teor a manutenção das fontes para produção e reprodução do homem e de suas atividades, neste sentido oportuniza uma relação de convivência entre homens e o ambiente para que todos possam desfrutar de recursos existentes e de oportunidades hoje á disposição. No entanto, para chegar ao equilíbrio, precisa-se de uma tomada de decisão na qual todos possam se envolver e cooperar com a implementação de ações transformadoras, em atitudes de cuidado e responsabilidade, a qual visa atender

\footnotetext{
${ }^{48}$ ZAMBAM, Neuro José. Amartya Sen, Liberdade, Justiça e Desenvolvimento Sustentável, p. 210.

49 ZAMBAM, Neuro José. Amartya Sen, Liberdade, Justiça e Desenvolvimento Sustentável, p. 211.
} 
BORGES, Bruna Adeli. A materialização do desenvolvimento sustentável, o direito ao lazer e a ideia de democracia. Revista Eletrônica Direito e Política, Programa de Pós-Graduação Stricto Sensu em Ciência Jurídica da UNIVALI, Itajaí, v.11, n.3, 30 quadrimestre de 2016. Disponível em: www.univali.br/direitoepolitica - ISSN 1980-7791.

as necessidades de um grupo social no espaço que se ocupa e, em estabelecer formas para que a sociedade se organize a partir da observância das condições dos recursos naturais, tecnológicos e do bem-estar social. Porém, o êxito ao desenvolvimento sustentável de uma sociedade deve ser avaliado segundo a Teoria do Desenvolvimento como Liberdade, através das chamadas liberdades substantivas em que os indivíduos de uma comunidade desfrutam. Essas liberdades substantivas são fruto do desenvolvimento, de modo que a falta de condições sociais e econômicas limitam a atuação do indivíduo impedindo-os de se desenvolver, manter-se adequadamente.

Considera-se que, para compreender o desenvolvimento sustentável, deve-se buscar o reconhecimento das diferenças, superar as desigualdades, manter um equilíbrio social e político, ter acesso à educação e a sistema de saúde universais, a independência na opção de preferências políticas, religiosas, culturais, conceber a permanente evolução da concepção moral e de seus valores mais importantes, sendo todos apresentados por múltiplas vozes o que trará um ideal nas garantias de liberdade constitutiva consolidadas em uma sociedade.

O direito ao lazer ao ser estabelecido no texto constitucional representa a necessidade para satisfação da expansão da liberdade humana e um direito fundamental. Assim, as políticas públicas devem garantir a proteção deste direito, pois a sua ausência atenta contra os valores da vida e de todos os demais direitos fundamentais da Carta de 1988.

Deste modo, trata-se da abordagem do direito social ao lazer na perspectiva da liberdade, analisando esta liberdade como um fator eficaz no processo da expansão das liberdades e defendendo como uma abordagem específica para o desenvolvimento. Quando analisadas dentro das políticas públicas há que ser feita por meio das liberdades individuais e do comprometimento social, juntamente com os direitos sociais e econômicos, inclusive a não discriminação entre pessoas de raças diferentes, entre homens e mulheres, pois todos devem ter o direito à liberdade básica e à liberdade substantiva de expressão. O lazer como um valor básico das sociedades democráticas, as quais buscam a garantia da igualdade de direitos, a liberdade e a valorização da diversidade. Com a 
BORGES, Bruna Adeli. A materialização do desenvolvimento sustentável, o direito ao lazer e a ideia de democracia. Revista Eletrônica Direito e Política, Programa de Pós-Graduação Stricto Sensu em Ciência Jurídica da UNIVALI, Itajaí, v.11, n.3, 30 quadrimestre de 2016. Disponível em: www.univali.br/direitoepolitica - ISSN 1980-7791.

promulgação da Constituição Federal de 1988, mas avançada no que se refere à ampliação dos direitos sociais a toda população brasileira, incluindo em especial o direito ao lazer em que o Estado deve proporcionar meios efetivos à sua concretização.

Por fim, a democracia assegura o vigor e o dinamismo de sua atuação na capacidade de complementar as variadas formas de manifestação dos interesses que integram a dinâmica da sociedade, preocupa-se com o atendimento das necessidades imediatas. A democracia possibilita para a sociedade uma dinâmica especial que garante a todos os cidadãos o exercício da liberdade. A essência da Democracia funda-se na ideia de que a decisão deve abranger a escolha da maioria, de maneira a cumprir a função de ser modelo de governo eficiente para o povo.

\section{REFERÊNCIAS DAS FONTES CITADAS}

BOBBIO, Noberto. O futuro da democracia; uma defesa das regras do jogo. Trad. Marco Aurélio Nogueira. Rio de Janeiro: Paz e Terra, 1986.

BOBBIO, Norberto; MATTEUCCI, Nicola; PASQUINO, Gianfranco. Dicionário de Política. Brasília: UNB, 1992

BONAVIDES, Paulo. Ciência Política. São Paulo: Editora Malheiros, $10^{a}$ Ed, 2000.

BRASIL. Ministério do Meio Ambiente. Política de Educação Ambiental. A Carta da Terra. Disponível em: http://www.mma.gov.br/destaques/item/8071-carta-daterra. Acesso dia 26 de novembro de 2015.

CHEMIN, Beatris Francisca. Políticas públicas de lazer: o papel dos Municípios na sua implementação. Curitiba: Juruá, 2007.

DAHL, Robert. Sobre a democracia. Brasília: UnB, 2009

DUMAZEDIER, Jofre. Sociologia empírica do lazer. Tradução Silvia Mazza. São Paulo: Perspectiva, 1999.

FONTANA, Odisséia Aparecida Paludo; MEZZAROBA, Orides. Accountability como mecanismo para o exercício da democracia inclusiva através das atribuições do Conselho Nacional de Justiça. In. ROVER, Aires José; GALINDO, Fernando; MEZZAROBA, Orides. Direito, Governança e Tecnologia: princípios, políticas e normas do Brasil e da Espanha. Florianópolis: Conceito Editorial, 2014. 
BORGES, Bruna Adeli. A materialização do desenvolvimento sustentável, o direito ao lazer e a ideia de democracia. Revista Eletrônica Direito e Política, Programa de Pós-Graduação Stricto Sensu em Ciência Jurídica da UNIVALI, Itajaí, v.11, n.3, 30 quadrimestre de 2016. Disponível em: www.univali.br/direitoepolitica - ISSN 1980-7791.

GOMES, Cristianne; OSORIO, Esperanza; PINTO, Leila; ELIZALDE, Rodrigo. Organizadores. Lazer na América Latina. Belo Horizonte: Editora UFMG, 2009.

MARCELLINO, Nelson Carvalho. Lazer e educação. $3^{a}$ ed. São Paulo: Papirus, 1995.

MARCELLINO, Nelson Carvalho. Lazer e humanização. $3^{a}$ ed. São Paulo: Papirus, 1983.

MONTESQUIEU, Charles de Secondant. O espírito das leis. São Paulo: Martins Fontes, 2000.

NOVAIS, Washington. Agenda 21: um novo modelo de civilização. In MELLO, Celso de Albuquerque. Anuário: Direito e Globalização, 1: a soberania. Rio Janeiro: Renovar, 1999.

PASOLD, Cesar Luiz. Metodologia da pesquisa jurídica: teoria e prática. 12. ed. Florianópolis: Conceito Editoria/Millenium, 2011.

RAWLS, John. O direito dos povos. Tradução Luís Carlos Borges. São Paulo: Martins Fontes, 2001.

SANTOS, Boaventura de Souza. Democratizar a democracia: os caminhos da democracia participativa. Rio de Janeiro: Civilização Brasileira, 2002.

SEN, Amartya. A idéia de justiça. Trad. Denise Bottmann, Ricardo Doninelli Mendes. São Paulo: Companhia das Letras, 2011.

SEN, Amartya. Desenvolvimento como liberdade. Trad. de Laura Teixeira Motta. São Paulo: Companhia das Letras, 2013.

SILVA, José Afonso. Comentário contextual à Constituição. São Paulo: Malheiros, 2005.

STAFFEN, Márcio Ricardo. Interfaces do Direito Global. Rio de Janeiro: Editora Lumen Juris, 2015.

STAFFEN, Márcio Ricardo. Direito Global: Humanismo e Direitos Humanos. Revista do Mestrado em Direito da Universidade Católica de Brasília, v. 10, n. 1, p. 178-208, jan./jun. 2016.

ZAMBAM, Neuro José. Amartya Sen, Liberdade, Justiça e Desenvolvimento Sustentável. Passo Fundo: IMED Editora, 2012.

ZAMBAM, Neuro José; AQUINO, Sérgio Ricardo de. Tolerância: Reflexões Filosóficas, Políticas e Jurídicas para o Século XXI. Revista da AJURIS - v. 42 - n. 137 - mar. 2015. p. 375. 
BORGES, Bruna Adeli. A materialização do desenvolvimento sustentável, o direito ao lazer e a ideia de democracia. Revista Eletrônica Direito e Política, Programa de Pós-Graduação Stricto Sensu em Ciência Jurídica da UNIVALI, Itajaí, v.11, n.3, 30 quadrimestre de 2016. Disponível em: www.univali.br/direitoepolitica - ISSN 1980-7791.

ZAMBAM, Neuro José. Desenvolvimento Sustentável: direito dos cidadãos e compromissos de todos. In: TRINDADE, André Karam; ESPINDOLA, Ângela Araújo da Silveira; BOFF, Salete Oro. Direito, Democracia e Sustentabilidade. Passo Fundo. IMED Editora, 2013.

ZAMBAM, Neuro José. A democracia contemporânea: entre a cruz e a espada. In: TRINDADE, André Karam; ESPINDOLA, Ângela Araújo da Silveira; BOFF, Salete Oro. Direito, Democracia e Sustentabilidade. Anuário do Programa de PósGraduação Stricto Sensu em Direito da Faculdade IMED. Passo Fundo. IMED Editora, 2014.

Submetido em: setembro/2016

Aprovado em: novembro/2016 